\title{
Green zero valent iron nanoparticles dispersion through a sandy column using different injection sequences
}

\author{
AntónioSoares \\ SandraRamos \\ TomásAlbergaria \\ CristinaDelerue-Matos
}

\begin{abstract}
The contamination of soils is a global environmental problem that urges an increased effort to recover polluted sites. In Europe, there are an estimated 20,000 polluted sites that need to be remediated and around 350,000 sites that are classified as potentially contaminated by the European Environment Agency (EEA). Remediation is a part of the solution to this problem, requiring the most innovative and sustainable technologies. In this context, the use of zero valent iron nanoparticles ( $\mathrm{nZVI}$ ) is a promising, low cost and efficient technology for the remediation of soil and groundwater contaminated with a wide range of organic and inorganic pollutants. Among the nZVIs, the ones produced using Green synthesis methods (green nZVIs (gnZVI)) using natural extracts, such as green tea, are increasingly considered an alternative technology for the future. However, there are issues related to the application of gnZVI in soil that are still not fully understood, requiring further research, among these is the study of their transport in soils.
\end{abstract}

Therefore, this work aims to study the transport of gnZVIs in sandy soils under diverse conditions such as soil particle size, soil saturation level and injection sequence. Several experiments were performed in an acrylic column with two sandy soils with different particle sizes (between 0.5 and $1.0 \mathrm{~mm}$ and higher than $1.0 \mathrm{~mm}$ ), using two distinct water saturation conditions (saturated and dry) and four injection sequences. After these tests the distribution of the gnZVI along the soil column was determined by atomic absorption spectroscopy. This work allowed concluding that the injection sequence might be one of the most important factors influencing the rate of $\mathrm{nZVI}$ dispersion through a sandy column. According to the results it was possible to propose, for distinct types of contamination (deep, superficial, hot spot or dispersed), the most appropriate injection sequence.

\section{Keywords}

Nanoparticles; nZVI; Green synthesis; Dispersion; Mobility; Soil contamination

\section{Introduction}

Nanoparticles (NPs) are defined as any particle that has at least one dimension between 1 and $100 \mathrm{~nm}$ (Christian et al., 2008). These materials can be classified according to their origin: natural (biogenic, geogenic, atmospheric or pyrogenic) or man-made materials (engineered or unintentionally produced as by-products) (Matlochova et al., 2013); or according to the NP composition: inorganic or carbon-based (Tratnyek and Johnson, 2006; Nowack and Bucheli, 2007). Nowadays, NPs are used in a wide range of applications such as electronics, medicine, pharmaceutical products and environmental applications. Among these materials, metallic iron NPs are widely accepted by many users and regulatory agencies because of their low production costs and high reactivity (Zhang, 2003). Over the last years, extensive laboratory studies have demonstrated that zero valent iron nanoparticles (nZVI) can be used to decompose or stabilize several and distinct contaminants such as halogenated hydrocarbons (Zhang, 2003; Nurmi et al., 2005), polychlorinated biphenyls (Varanasi et al., 2007), organochlorine pesticides (Elliott et al., 2003), organic dyes (Liu et al., 2005), various inorganic compounds (Cao et al., 2005), and distinct metal ions (Li et al., 2017).

$\mathrm{nZVI}$ can be synthesized through bottom-up or top-down methods. The green bottom-up method is the one that is becoming more attractive and is gathering the attention of the scientific community (Machado et al., 2013). The Green synthesis is based on the use of plant extracts or other natural products or wastes (such as wastes from the juice industry, namely citrines peel, albedo and pulps) which promote the reduction of iron salts and the subsequent formation of nZVI (Machado et al., 2014). Husen and Siddiqi (2014) reported that extracts from almost all plants (herbs, shrubs or trees) that contain aromas, flavonoids, phenols, alcohols and proteins can produce metal NPs when reacting with the correspondent metal salt. The Green synthesis is environmentally friendly because a toxic reagent (sodium borohydride) is replaced by a natural extract, that in this case is inexpensive (Machado et al., 2013), and it's procedure is simple and easy to implement on a large scale (Machado et al., 2014). 
The use of the Green synthesis was first applied by VeruTEK and USEPA (Hoag et al., 2009) using plant extracts (coffee, green tea, black tea, lemon, balm, sorghum, bran, grape etc.) with high antioxidant capacities, mainly because of the presence of polyphenols, that react with iron (II) solution, producing nZVI. Machado et al. (2013) concluded that the production of nZVI can be improved using plant leaves with low moisture contents. On the other hand, Mystrioti et al. (2015) and Kozma et al. (2016) observed the formation of other forms of iron (namely oxides or hydroxides) that can lead to a higher aggregation, resulting in a lack of mobility in porous systems (Huang et al., 2014).

The success of a remediation in which injected $\mathrm{nZVI}$ are used depends on their mobility in the porous media, the contact between the $\mathrm{nZVI}$ and the contaminant, its reactivity and the impact of the material on the contaminated ecosystem (Husen and Siddiqi, 2014). If $\mathrm{nZVI}$ is exposed to air or water, several processes, including break-downs and auto-reduction within the oxide shell can occur (Hoerle et al., 2004), in the case of aqueous systems nZVI is oxidized to Fe2+ (fast process) and/or Fe3+ (slower process) (Tosco et al., 2014). These phenomena result in a loss of zero valent iron content (Liu and Lowry, 2006; Sarathy et al., 2008), decreasing the capacity to react with a target contaminant. In addition, the nZVI particles may aggregate and a new, mixed-valence (Fe2+/Fe3+) oxide layer (Sarathy et al., 2008) can be formed. According to Zhao et al. (2016) several factors affect the size and stability of nZVI, including: temperature, natural organic matter, pH, ionic strength and type and concentration of stabilizers (He and Zhao, 2008; Zhang et al., 2011). Different conditions are proven to affect the reactivity of nZVI namely the surface area (Nurmi et al., 2005), the age of the NP (Liu and Lowry, 2006), the $\mathrm{pH}$ of the aqueous phase (Song and Carraway, 2005; Liu and Lowry, 2006), the use of stabilizers (He and Zhao, 2005; He et al., 2010; Sakulchaicharoen et al., 2010) and the concentrations of the contaminants and other reactive groundwater constituents (Liu et al., 2005; Song and Carraway, 2005).

In the last decade, several field tests using nZVI have been performed to evaluate their efficiency in degrading distinct contaminants and to understand their mobility along the soil matrix (Quinn et al., 2005). However, in several of these field tests poor nZVI mobility was observed, probably due to several interactive forces between the NPs and the soil particles and due to soil pore blockage because of nZVI agglomeration (Quinn et al., 2005; Bennett et al., 2010). Even in laboratory experiments conditions nZVI tends to aggregate, producing clusters that can reach colloidal sizes (several micrometers) that limits their remediation potential (Ryan and Elimelech, 1996; Kharisov et al., 2012). Without the application of surface coatings to aid colloidal stability, rapid aqueous aggregation of standard nZVI is frequently observed (Schrick et al., 2004). When the size of the NPs is similar or larger than the soil pores, they become trapped, thus the transport will likely be reduced by straining, filtration or sedimentation by the establishment of interactions between the soil-water and soil matrix (Nowack and Bucheli, 2007; Fang et al., 2009). Consequently larger aggregates might be retained in the upper soil layers (Fang et al., 2009). The retention mechanisms in the unsaturated zone are even more complex than in the saturated zone, mainly due to the presence of an air phase in the system (Bradford and Torkzaban, 2008). In the former, water flow is restricted by capillary forces to the smaller regions of the pore space and flow rates are relatively small (Bradford and Torkzaban, 2008), where the transport may be influenced by increased attachment to the solid-water interface (Chu et al., 2001), attachment to the air-water interface (Cherrey et al., 2003), film straining in water films enveloping the solid phase (Saiers and Lenhart, 2003), and retention at the solid-air-water triple point (Steenhuis et al., 2006). Moreover, transients in water content during infiltration and drainage processes can also play a significant role (Saiers and Lenhart, 2003).

Bennett et al. (2010) concluded that the mobility of the nZVI decreased over time, making it necessary to pump the groundwater to force the nZVI towards the contaminated hot zone. Quinn et al. (2005) also observed that emulsified nZVI were not evenly distributed within the target treatment area and did not percolated as far as it was previously expected. Following this, He and Zhao (2005) stated that the soil mobility or deliverability is the most prominent technical obstacle of the application of nZVI in soils.

The knowledge of the mobility of NPs in porous media and the processes that affect their movement is limited, especially for unsaturated ones, mostly due to the complex nature of the interactions between the NPs and the soil matrix (Tiede et al., 2009; Tourinho et al., 2012). In order to understand the mobility of nZVI in sandy soils and the factors that affect their movement, this work aimed to study the influence of moisture content, particle size and the green nZVI injection sequence on the dispersion of the $\mathrm{nZVI}$ along a sandy soil column. 
This paper describes the first work of a wider project concerning the study of the transport of gnZVI in distinct types of soils, evaluating the impact of several operational (sequence and location of injection) and physico-chemical (such as clay, sand and organic matter contents) parameters on the gnZVI distribution in soils. This first work focused on the study of the transport of gnZVIs in sandy soils where different injection sequences were tested.

\section{Materials \& methods}

\subsection{Reagents and solutions}

Iron (III) chloride was obtained from Merck. Type II deionized water (resistivity $=15.0 \mathrm{M} \Omega \mathrm{cm}$ ) was used throughout the study and was obtained from an Elix 3 Advantage system (Millipore). Black tea (Tetley) was used to produce the extracts. A $0.1 \mathrm{M}$ iron (III) chloride solution was prepared and used to synthesize nZVI.

\subsection{Analysis of iron}

The quantification of the iron in the soil samples was performed using an Analytik Jena CONTRAA 700 atomic absorption spectrometer. Aspect CS 1.5.6 software was used to acquire and process all the data. For the quantification of iron the external standard calibration method was used. All the measurements were performed in triplicate, presenting relative standard deviations below $4.6 \%$.

\subsection{Sand column preparation}

For the experimental tests an acrylic column (h: $45 \mathrm{~cm}$, i.d.: $2 \mathrm{~cm}$ ) was used. $280 \mathrm{~g}$ of sand (either dry or saturated) was inserted in the column, for each experiment, roughly corresponding to a $36 \mathrm{~cm}$ column height. The sand was collected on a beach in the Porto district, in the North of Portugal. The sand was washed, dried and sieved using two sieves: openings of 0.5 and 1.0 mm respectively. Following this, two portions of sand were selected for the tests: Sand 1 - particle sizes between 0.5 and $1.0 \mathrm{~mm}$; and Sand 2 - particles sizes higher than $1.0 \mathrm{~mm}$. Two limit moisture content situations were experimented: saturated and dry. For the dry sand experiment the sand was dried at $105^{\circ} \mathrm{C}$ for $24 \mathrm{~h}$, while for the saturated experiments $70 \mathrm{~mL}$ of water was added to the sand before its use (a preliminary analysis revealed that this volume led to the saturation of this type of sand). To assure homogenization, the soil was mixed with the water for $5 \mathrm{~min}$.

\subsection{Tea extract preparation}

A $0.9 \mathrm{~g}$ mass of black tea leaves (Tetley) was weighed and transferred to a $100-\mathrm{mL}$ Erlenmeyer flask to which $100 \mathrm{~mL}$ of water was added. The flask was then placed in a shaker bath (Stuart Scientific, SBS30) at $80^{\circ} \mathrm{C}$ for 20 min, as suggested by Machado et al. (2013). The mixture of this tea extract with the ferric solution allowed the reduction of the Fe3+ leading to the formation of gnZVI as described by Hoag et al. (2009) and Machado et al. (2013).

\subsection{Column experiments}

$\mathrm{nZVI}$ reacts rapidly with a wide range of contaminants but also with atmospheric oxygen and soil matrix constituents. Therefore Machado et al. (2015) suggested that the nZVI should be synthesized within the soil matrix and exactly in the contaminated zone in order to guarantee that as soon as the $\mathrm{nZVI}$ is formed it starts to react with the contaminants. Following this, the nZVI synthesis occurred inside the soil with sequential but immediate $(<30 \mathrm{~s})$ injections of the $0.1 \mathrm{M}$ iron (III) solution $(1.5 \mathrm{~mL})$ and the extract $(30 \mathrm{~mL}), 5 \mathrm{~cm}$ below the sand surface (Fig. 1). 


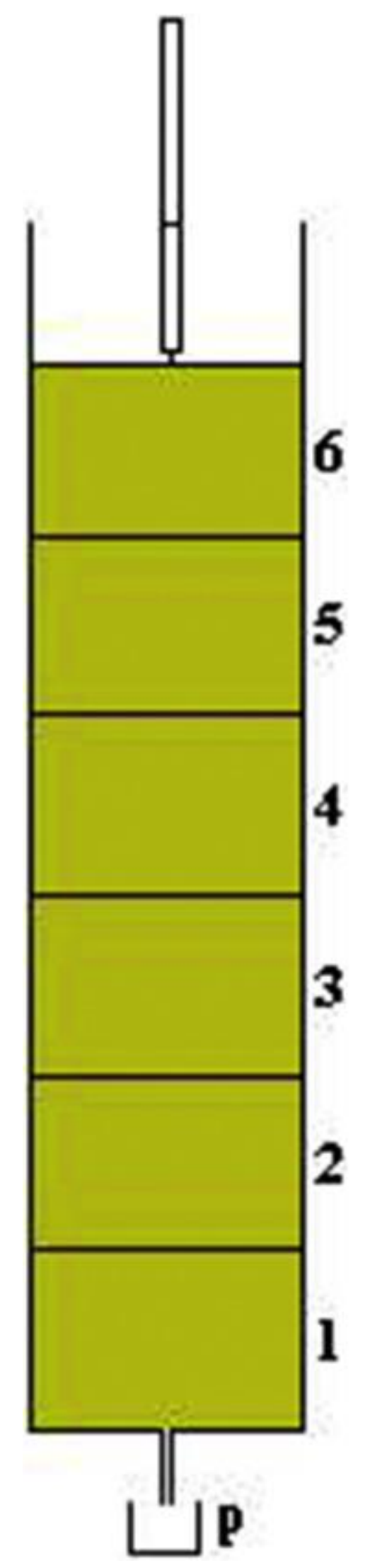

fig. 1 Soil column and injection system

After the injection of both solutions, the column was left for $1 \mathrm{~h}$, allowing the solutions to percolate through the column and to reach equilibrium. 16 different experiments were performed (Table 1), in which four injection sequences were tested, varying the order and amount of tea extract and iron solution. The four different injection sequences used in this work were: Sequence A - injection of $50 \%$ of the volume of extract + injection of $100 \%$ of the volume of Iron (III) solution and finally the remaining $50 \%$ of extract; Sequence B injection of $100 \%$ of Iron (III) solution and then $100 \%$ of extract; Sequence C - similar to Sequence B but changing the order of the solution injected and Sequence D - injection of $50 \%$ of Iron (III) solution, then $100 \%$ of extract and finally $50 \%$ of Iron (III) solution. 
Table 1. Characteristics for each essay regarding injection sequence, particle size, and water content.

\begin{tabular}{llll} 
Experiment & Soil particle size $(\mathrm{mm})$ & Water saturation level & Injection sequence \\
\hline 1 & {$[0.5-1.0]$} & Dry & A \\
2 & {$[0.5-1.0]$} & Saturated & A \\
3 & $>1.0$ & Dry & A \\
4 & $>1.0$ & Sturated & A \\
5 & {$[0.5-1.0]$} & Dry & B \\
6 & {$[0.5-1.0]$} & Saturated & B \\
7 & $>1.0$ & Dry & B \\
8 & $>1.0$ & Saturated & B \\
9 & {$[0.5-1.0]$} & Dry & C \\
10 & {$[0.5-1.0]$} & Saturated & C \\
11 & $>1.0$ & Dry & C \\
12 & $>1.0$ & Saturated & C \\
13 & {$[0.5-1.0]$} & Dry & D \\
14 & {$[0.5-1.0]$} & Saturated & D \\
15 & $>1.0$ & Dry & D \\
16 & $>1.0$ & Saturated & D \\
\hline 16 & & &
\end{tabular}

In the end of the test, the detachable bottom of the column was removed and the soil was divided in six layers, the first layer corresponded to the bottom layer of the column and the last layer to the top layer (designated by Layers 1 to 6), as shown in Fig. 1. At the end of each test the excess of solution that percolated and flowed out from the bottom of the column (designated by Layer P) was collected. To guarantee the total extraction of the iron, each soil layer was mixed with $50 \mathrm{~mL}$ of a hydrochloric acid solution $(\mathrm{pH}=2)$ and after magnetic stirring (VWR Advanced VMS-C7) for $10 \mathrm{~min}$, and was analysed by atomic absorption spectrometry.

Prior to quantification the soil extracts were filtered using nylon filters (Simplepure, d: $25 \mathrm{~mm}$; pore diameter: $0.22 \mu \mathrm{m}$ ) in order to remove small soil particles that could affect the absorbance measurements. All the experiments were performed in duplicate, presenting relative standard deviations below $6.9 \%$.

\section{Results and discussion}

The interest of $\mathrm{nZVI}$ as remediation agent rose from their smaller size and consequent improved soil mobility performance and better chemical and physical properties when compared with the millimeter-sized "conventional" ZVI (Cook, 2009). Moreover, limited mobility in water-saturated porous media reduces the ability to deliver nZVI dispersions in the subsurface (Phenrat et al., 2007). Therefore, it is essential to understand the $\mathrm{nZVI}$ 's behavior in soils and to develop adequate injection strategies of the reagents to form $n Z \mathrm{VI}$ to overcome the limitation mentioned above.

\subsection{Experimental setup basics and nZVI synthesis}

To evaluate the nZVI dispersion and mobility through the soil, three different factors were studied: the soil particle size, the injection sequence of the reagents and the water saturation level.

According to Machado et al. (2013), the optimal ratio (V:V) of tea leaves extract and iron (III) solution is $20: 1$, thus for the $1.5 \mathrm{~mL}$ of $0.1 \mathrm{M}$ iron (III) solution injected in each experiment, $30 \mathrm{~mL}$ of extract were used to promote and assure the complete reaction with the iron (III) 
and to synthesize $\mathrm{nZVI}$. The production of $\mathrm{nZVI}$ was possible at ambient temperature, allowing the in situ $\mathrm{nZVI}$ synthesis and reducing/eliminating the cost of offsite synthesis, storage and transport (Hoag et al., 2009).

\subsection{Column experiments and influencing factors}

NP transport is highly influenced by Brownian motion, that increases for particles with smaller sizes and that can increase the probability of collisions between the NPs and the soil channels (Dunphy Guzman et al., 2006). One of the most significant obstacles for a wider application of $\mathrm{nZVI}$ particles in soil remediation is their tendency to easily and rapidly aggregate. In aqueous solutions the agglomeration of unstabilized nZVI occurs in the first 2-15 min after injection and in the following 30 min nZVI rapidly settle (He and Zhao, 2005; Saleh et al., 2005; Phenrat et al., 2007).

Column experiments performed with relatively low concentrations of unstabilized nZVI $(0.1-0.3 \mathrm{~g} / \mathrm{L})$ showed that the NPs have poor stability and mobility along the column due to the absence of a sufficient electro-static energy barrier to prevent large aggregates from forming and depositing (Schrick et al., 2004; Saleh et al., 2007; Tiraferri and Sethi, 2009). Delivering nZVI through porous media becomes more challenging when higher concentrations are used because of the higher extent of particle aggregation and consequent retention. This has been observed in several field applications in which concentrations ranging from 1.0 to $30 \mathrm{~g} / \mathrm{L}$ are typically used (Quinn et al., 2005; Bennett et al., 2010; He et al., 2010; Wei et al., 2010). Indeed, early pilot scale field trials have indicated extremely poor nZVI subsurface migration, with maximum practical transport distances of only a few metres reported for bare unsupported particles in saturated sediments (Schrick et al., 2004).

\subsubsection{Influence of injection sequence on nZVI mobility}

The use of gnZVI for the remediation of contaminated soils implies their production in the soil, specifically in the contaminated zone. This will be achieved through the separate injection of the extract and the iron solution, producing gnZVI. However, for this in situ production it is important to understand how the injection sequence affects the gnZVI distribution in the soil matrix as well as some soil properties such as moisture content and porosity. According to Machado et al. (2015) the volume ratio of extract:iron solution used in this work guarantees the complete conversion of the ionic iron to zero-valent iron. As stated before, four distinct injection sequences were tested, varying the injection order and the volume of the solutions:

Sequence A (50\% Extract $+100 \%$ Iron $+50 \%$ Extract) in which in a first stage the gnZVI were synthesized and with the second injection of the extract the synthesis was completed and allowed the transport of the gnZVI to deeper zones of the column. Fig. 2 shows the results obtained in the tests using sequence $A$, where the percentage of iron corresponds to the fraction of the total amount of iron injected in the column that was found in each layer.
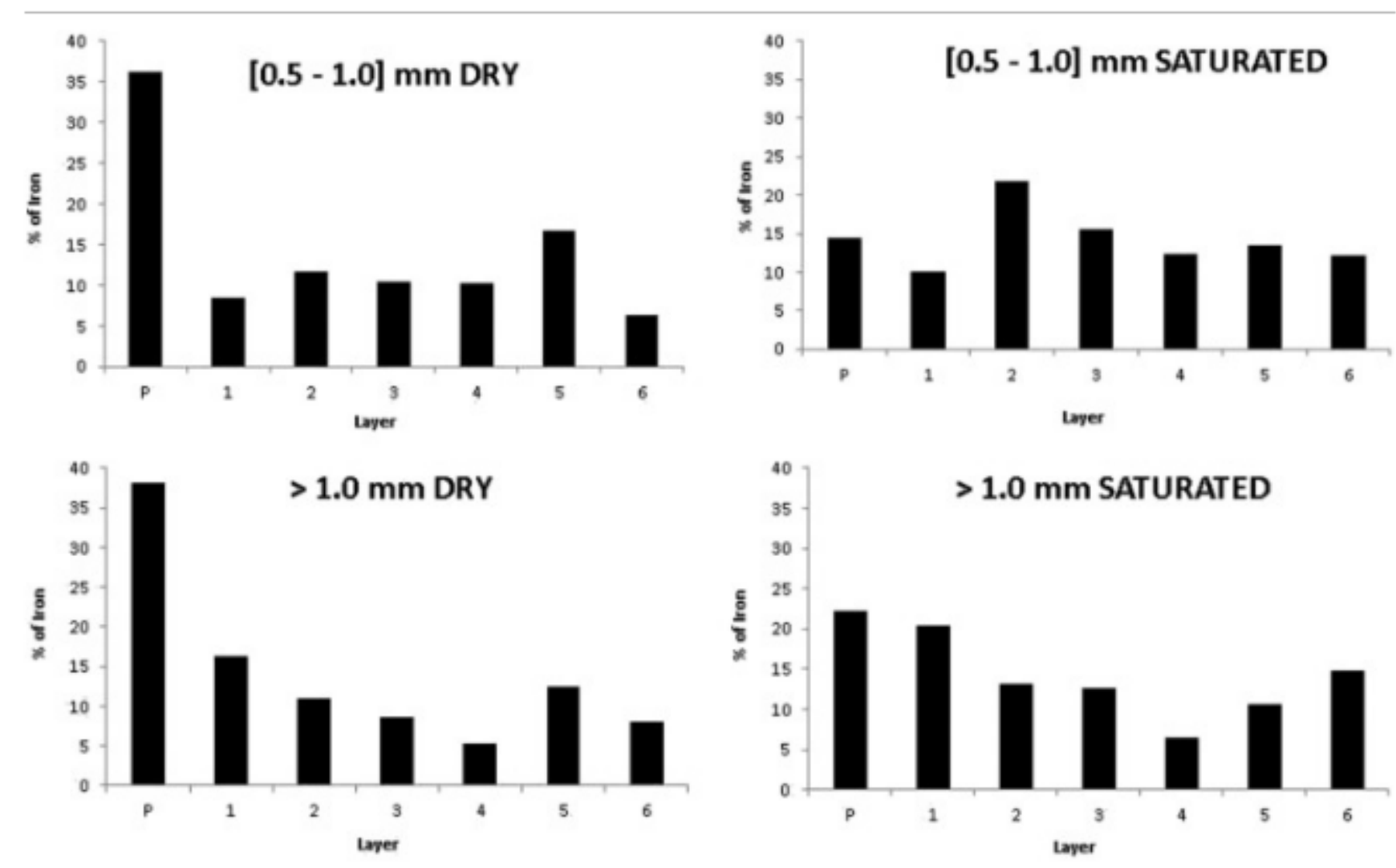
The results show that between 15 and $38 \%$ of the gnZVIs were found in the sample collected at the bottom of the column, meaning that they moved along the entire column. This movement could be due to percolation or transport promoted by the final injection of extract that acted as a flushing solution, as observed in Saberinasr et al. (2016). The remaining iron was found to be distributed, with no significant differences, along the column layers. The amounts of iron along the column were higher in the saturated test because its movement is hindered by the decrease of the porosity and permeability of the soil, leading to a more restricted transport of the nanoparticles. Considering these results, it can be concluded that this type of injection sequence could be appropriate in cases where the contamination is spread vertically along a dry soil.

Sequence D (50\% Iron + 100\% Extract + 50\% Iron) was similar to Sequence A, but the order in which the solutions were injected was switched. Comparing sequences $A$ and $D$ for the same type of experiments (Fig. 2, Fig. 3), in sequence $D$ the amount of iron that reached the bottom of the column (layer $P$ ) was lower than the amount in sequence $A$. In sequence $D$ the first injection of iron did, in fact, percolated to the lower layers of the column while the second one aimed to remain in the more superficial layers. These tests showed that this sequence guarantees the transport of iron through the soil column while obtaining an even distribution of iron through the entire soil. However, the amounts of iron in each layer of the soil column were lower when sequence D was used, for the test with different moisture content and particle size (Fig. 3). Considering these results, it can be concluded that this injection sequence is appropriated when there are superficial hot zones and when the contaminants are dispersed along the soil.

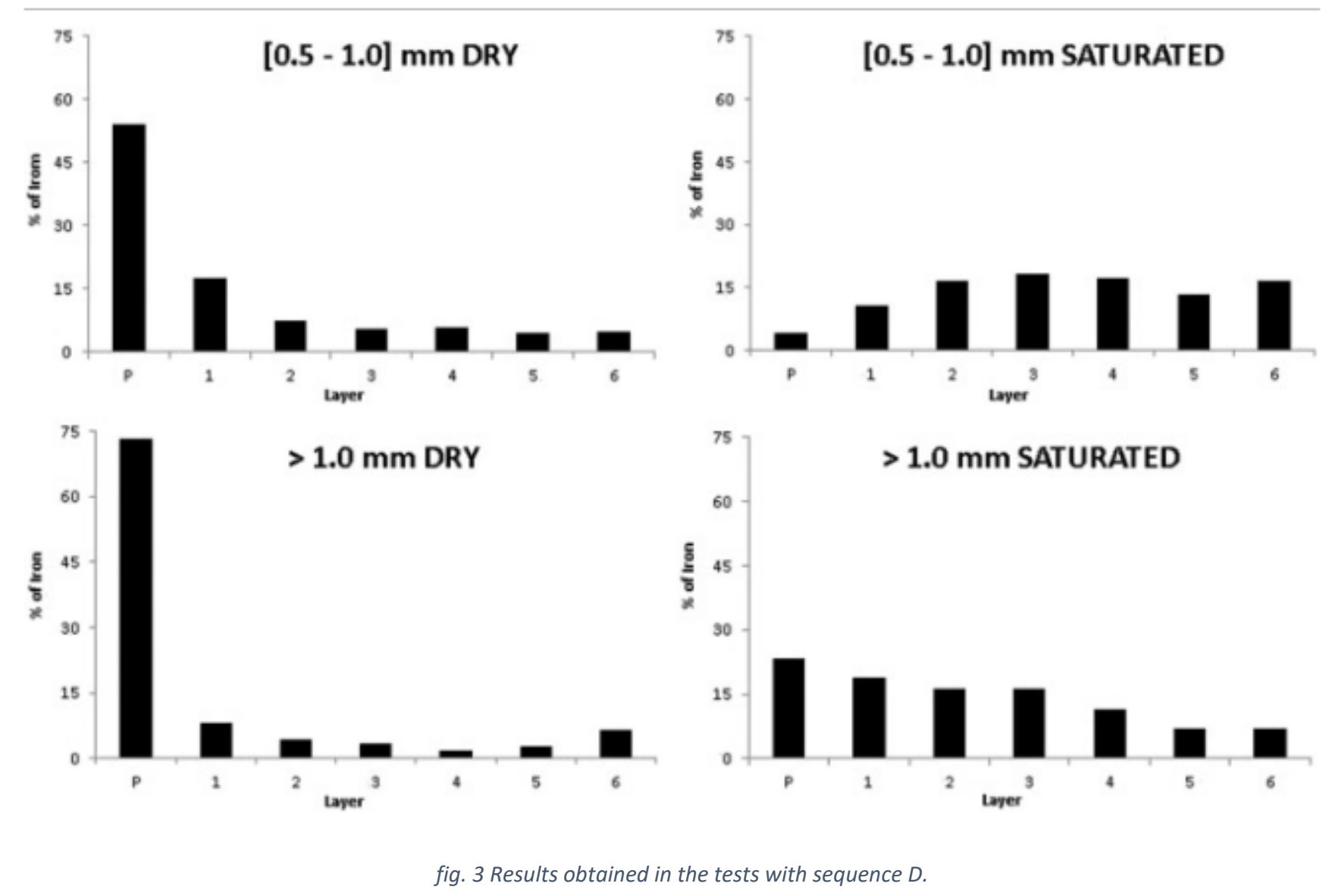

In sequences $B$ and $C$ the total volume of each solution was injected at once, in sequence $B$, first the iron solution and then the extract and in sequence $C$ the extract followed by the iron solution.

Sequence B showed, especially for the dry soil experiments, a high percentage of iron in layer $\mathrm{P}$, indicating that this iron moved through the entire column. For example in the test performed with the dry soil with particles larger than $1 \mathrm{~mm}, 73 \%$ of the iron reached the bottom of the column. This is due to the fact that this soil had the highest porosity, guarantying excellent transport conditions for the gnZVI. In the opposite situation, i.e. for the saturated soil with particles ranging from $0.5-1.0 \mathrm{~mm}$, the percentage of iron in layer $P$ was the lowest. Fig. 4 also shows that the percentage of iron in the soil different layers does not vary significantly. Therefore, this sequence could be appropriate for deep contaminations in dry sandy soils and for dispersed contaminations in saturated sandy soils. 

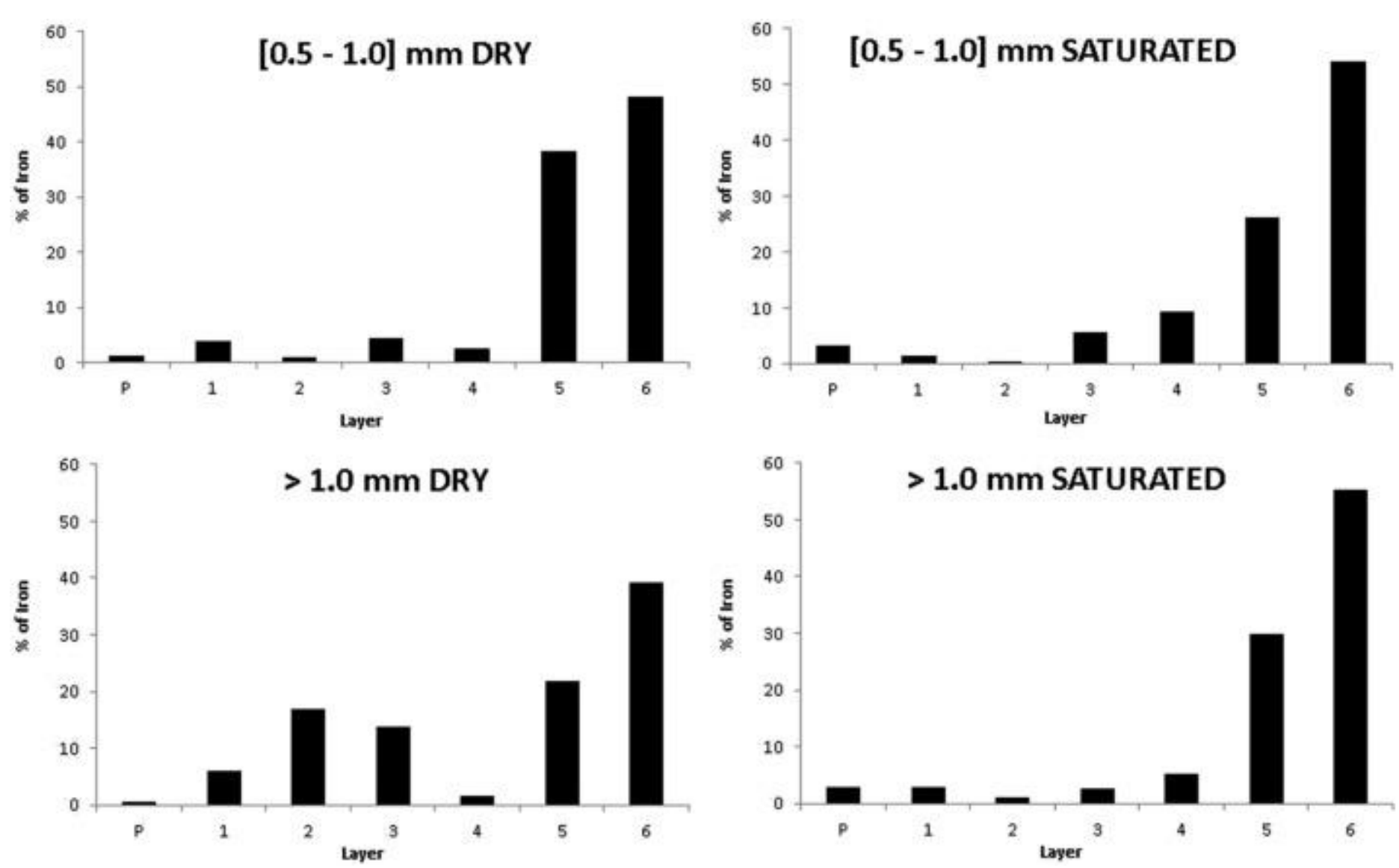

fig. 4 Results obtained in the tests with sequence $B$

Two major differences were observed between Sequence $C$ and Sequence B: the lower percentages of iron found in layer $P$ (maximum of 3.3\%) and, due to the injection characteristics, the accumulation of the injected iron in the top layers of the column (Fig. 5). So, there is no guarantee that the iron reaches all zones of the soil, accumulating in a more superficial layer of the soil what can make this sequence appropriate for sandy soils with superficial hot spot contaminations.
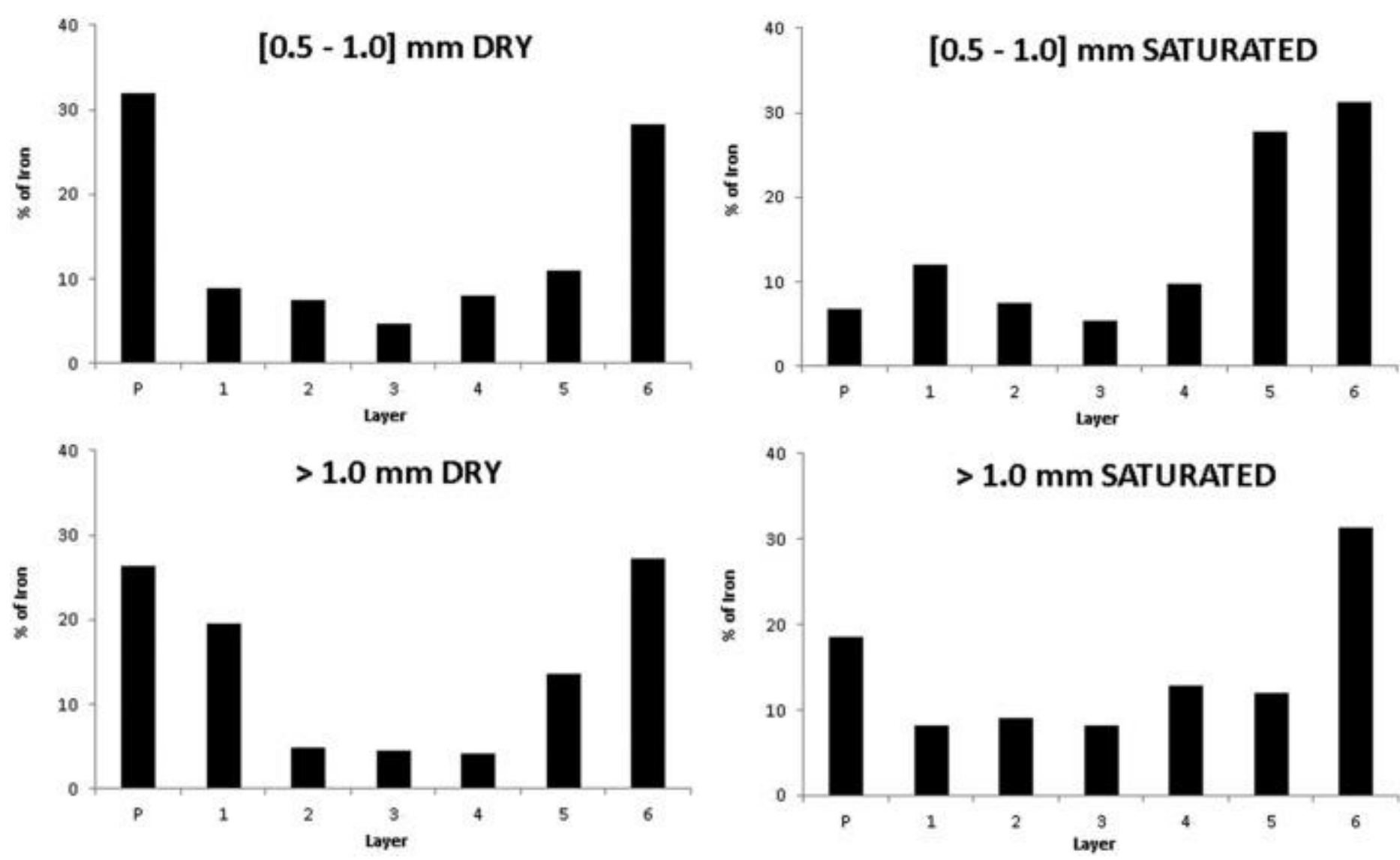

fig. 5 Results obtained in the tests with sequence $C$.

\subsubsection{Influence of soil water saturation}

The impact of the soil water saturation level on the transport of $n Z V I$ in soils has not been sufficiently studied, so the knowledge regarding the movement of nanoparticles in unsaturated soils is still scarce. In this work it was evaluated the transport of nZVI in saturated and in dry soils aiming to identify which type of injection sequence would be more appropriate for each soil.

All the experiments performed allowed to study the impact of water saturation on the application of $\mathrm{nZVI}$ in a sandy soil matrix. When compared, the tests performed with distinct saturations conditions for the same injection sequence and for the same soil (same particle sizes) it can be observed that in saturated experiments a lower percentage of iron was found in the $P$ layer. In the dry soil experiments the flow paths were all clear, allowing a free movement of the nZVI. This did not occur in the saturated experiments where the spaces in the soil were filled with water, presenting a hindrance to the nZVI flow along the soil column. This shows that in saturated soils the percolation and transport of $\mathrm{nZVI}$ is more difficult than in dry soils. The amount of iron that reached the bottom of the column was higher in the tests using injection sequence B (50\%), less significant for tests with injection sequences $A$ and D (19 and $12 \%$, respectively) and insignificant for the tests with injection sequence $\mathrm{C}$. 
As a consequence, the iron remains retained in the upper layers of the soil increasing its contact with the soil matrix. The increase was insignificant in the tests performed with injection sequence $\mathrm{C}$ (the iron was injected at once, after the injection of the extract, limiting its transport to diffusion effects and gravitational forces) but extremely high in the experiments with injection sequence $\mathrm{B}$ (higher than $90 \%$, this sequence allowed an excellent percolation of iron in dry soils, however in saturated zones the easy transport was hindered, maintaining the iron in the soil), and moderate for tests with the injection sequences $A$ and $D(30$ and $23 \%$, respectively).

Because dry soils allow an easy transport of the $\mathrm{nZVI}$ along its matrix, it is possible to propose that:

For deep contaminations, injection sequence B could be used because it allows the nZVI to travel longer distances;-

For more superficial contaminations, injection sequence $C$ could be chosen because it concentrates the nanoparticles in the top layers;

-For more dispersed contamination, injection sequences $A$ and $D$ could be chosen and injection sequence $D$ is more appropriated for superficial dispersed contaminations.

In saturated soils the movement of the gnZVI showed to be more difficult but allowed a more homogeneous distribution along the soil column. Following this, it is possible to propose that:

For deep contaminations, injection sequence A could be used because it was in these tests that a higher amount of $\mathrm{nZVI}$ traveled through all column showing better transport conditions;

For more superficial contaminations, injection sequence $\mathrm{C}$ could be chosen for the same reasons indicated above;

For more dispersed contamination, injection sequences $A$ and $B$ can be selected because they present a more homogeneous distribution of iron among the layers.

\subsubsection{Influence of soil particles size}

Soil particle size has a significant impact on the transport and retention of nanoparticles in saturated and unsaturated soil (Kasel et al., 2013). The experiments performed with soils with different particles sizes (0.5-1.0 and above $1.0 \mathrm{~mm})$, using the same injection sequence and water saturation level, allowed to conclude that the amount of iron that was collected in layer $\mathrm{P}$ was higher for the experiments with higher particle size. This indicates that in soils with lower particle sizes the $\mathrm{nZVI}$ is more retained hindering its transport along the column. This was also observed in Sun et al. (2015) that studied the transport of other nanoparticles, and graphene oxide, in sand columns. Kasel et al. (2013) and Liang et al. (2013) explained that this retention/filtration effect can be attributed to the increase of the mass transfer of nZVI from the aqueous phase to the soil particle surface, as the particle size decreases. It should also be considered that the size of the nanoparticles could change during the experiments due to agglomeration, thus affecting its percolation through the sand column and consequently its transport. Darlington et al. (2009) found that particle aggregation was a determinant mechanism that limits the mobility of $\mathrm{nZVI}$. Three sub-mechanisms were then proposed: (i) particle aggregation and subsequent gelation caused by poor colloidal stability; (ii) the formation of voluminous corrosion product precipitates from particle oxidation/corrosion; and (iii) particle removal from solution by interaction with subsurface components. One of the main conclusions of this study was that the nanoparticles transport seemed to be dependent on its size, not the original but the agglomerate one.

$\mathrm{nZVI}$ agglomeration and retention in soils with smaller particles turn the nanoparticles less mobile and concentrated near the injection point or in a restricted area of the soil where the extract (as reacting and transport solution) pushed them to. The results obtained in these studies allow concluding that:

For soils with lower particle sizes, injection sequence C allowed to obtain an heterogeneous distribution of nZVI along the soil column, being preferentially concentrated near the injection point;

Using injection sequence $A$ it is possible to reach deeper zones of the soil, attending to the iron percentage in layer $\mathrm{P}$; 
In soils with larger soil particles, the amount that percolate through all the column is higher (with the exception of injection sequence $\mathrm{C}$ );

Injection sequences $\mathrm{A}$ and $\mathrm{B}$ showed good distribution of $\mathrm{nZVI}$, however sequence $\mathrm{B}$ might allow the treatment of deeper contaminations.

The data and knowledge obtained in this work allow us to understand how the injection sequence of the reagents to produce gnZVI influences its distribution in sandy soils. With this information and depending on the type of sandy soil or the location and extension of the contamination, the most appropriate injection sequence could be tuned. As stated before, the work here presented is included in a wider project that also includes the scale up of this technology, operating at a real contaminated site. This scale up operation will confirm or adjust the knowledge concerning the injection sequence of the reagents, allowing this technology to be closer to be applied in real situations with the necessary adjustments, namely the volume of solutions to achieve the required gnZVI distribution in soil, the number of injection wells and respective depths and the reactivity of the nanoparticles.

The level of agreement between the values obtained in the tests replicas was assessed using the intraclass correlation coefficient (ICC) and using the Wilcoxon signed rank test (pared case). All scenarios showed good reproducibility with ICCs close to 1 (perfect agreement). The P.values of the Wilcoxon test are not significant (ns) at a level of $5 \%$ (alternative hypothesis: true location of the differences shift is not equal to 0$)$.

\section{Conclusions}

The present study demonstrated that the transport of zero valent iron nanoparticles in soil is highly influenced by the soil properties such as particle size and water saturation level but also by the injection procedure for their synthesis. This information is of major importance for the nZVI application in contaminated soils because it could avoid poor distribution of the gnZVI through the contaminated area and can optimize process efficiency. From the results obtained in this work it is possible to conclude that:

Injection sequence A (injection of $50 \%$ of the volume of extract + injection of $100 \%$ of the volume of Iron (III) solution and finally the remaining $50 \%$ of extract) can be appropriate in cases where the contamination is spread vertically along the soil,

Injection sequence B (injection of $100 \%$ of Iron (III) solution and then $100 \%$ of extract) can be appropriate for deep contaminations in dry sandy soils and for dispersed contaminations in saturated sandy soils.

Injection sequence C (similar to Sequence B but changing the order of the solution injected) can be appropriate for sandy soils with superficial hot spot contaminations.

Injection sequence D (injection of $50 \%$ of Iron (III) solution, then $100 \%$ of extract and finally $50 \%$ of Iron (III) solution) can be appropriated for contamination cases with more superficial hot zones and with the contaminants dispersed along the soil.

Dry soils allow an easy transport of the $\mathrm{nZVI}$ along its matrix, while in saturated soils, the nZVI movement is more difficult but allow a more homogeneous distribution of iron along the soil column.

In soils with lower particle sizes the $\mathrm{nZVI}$ is more retained hindering its transport along the column.

\section{Acknowledgments}

António Soares is grateful to REQUIMTE for his postdoctoral research grant (associated to Project UID/QUI/50006/2013), as well as to FCT/MEC for funding through national funds, co-financed by the Fundo Europeu de Desenvolvimento Regional (FEDER), in the context of the partnership agreement PT2020. The authors also thank "Fundação para a Ciência e a Tecnologia" (Project UID/QUI/50006/2013) for the financial support for this work. 
Bennett et al., 2010

P. Bennett, F. He, D. Zhao, B. Aiken, L. Feldman

In situ testing of metallic iron nanoparticle mobility and reactivity in a shallow granular aquifer

J. Contam. Hydrol., 116 (2010), pp. 35-46

Bradford and Torkzaban, 2008

S.A. Bradford, S. Torkzaban

Colloid transport and retention in unsaturated porous media: A review of interface-, collector-, and pore-scale processes and models Vadose Zone J., 7 (2008), pp. 667-681

Cao et al., 2005

J.S. Cao, D. Elliott, W.X. Zhang

Perchlorate reduction by nanoscale iron particles

J. Nanopart. Res., 7 (2005), pp. 499-506

Cherrey et al., 2003

K.D. Cherrey, M. Flury, J.B. Harsh

Nitrate and colloid transport through coarse Hanford sediments under steady state, variably saturated flow

Water Resour. Res., 39 (2003)

Christian et al., 2008

P. Christian, F. Von der Kammer, M. Baalousha, T. Hofmann

Nanoparticles: structure, properties, preparation and behaviour in environmental media

Ecotoxicology, 17 (2008), pp. 326-343

Chu et al., 2001

Y. Chu, Y. Jin, M. Flury, M.V. Yates

Mechanisms of virus removal during transport in unsaturated porous media

Water Resour. Res., 37 (2001), pp. 253-263

Cook, 2009

S.M. Cook

Assessing the use and application of zero-valent iron nanoparticle technology for remediation at contaminated sites

Office of Solid Waste and Emergency Response, Office of Superfund Remediation and Technology Innovation (2009) 
Darlington et al., 2009

T.K. Darlington, A.M. Neigh, M.T. Spencer, O.T. Nguyen, S.J. Oldenburg

Nanoparticle characteristics affecting environmental fate and transport through soil

Environ. Toxicol. Chem., 28 (2009), pp. 1191-1199

Elliott et al., 2003

D. Elliott, J. Cao, W. Zhang, S. Spear

Nanoscale iron particles for perchlorate reduction

The 225th ACS National Meeting, New Orleans, LA, United States, 43 (2003), p. 564

Fang et al., 2009

J. Fang, X.-q. Shan, B. Wen, J.-m. Lin, G. Owens

Stability of titania nanoparticles in soil suspensions and transport in saturated homogeneous soil columns

Environ. Pollut., 157 (2009), pp. 1101-1109

Guzman et al., 2006

K.A.D. Guzman, M.P. Finnegan, J.F. Banfield

Influence of surface potential on aggregation and transport of titania nanoparticles

Environ. Sci. Technol., 40 (2006), pp. 7688-7693

He and Zhao, 2005

F. He, D.Y. Zhao

Preparation and characterization of a new class of starch-stabilized bimetallic nanoparticles for degradation of chlorinated hydrocarbons in water

Environ. Sci. Technol., 39 (2005), pp. 3314-3320

He and Zhao, 2008

F. He, D. Zhao

Hydrodechlorination of trichloroethene using stabilized Fe-Pd nanoparticles: reaction mechanism and effects of stabilizers, catalysts and reaction conditions

Appl. Catal. B Environ., 84 (2008), pp. 533-540

He et al., 2010

F. He, D. Zhao, C. Paul

Field assessment of carboxymethyl cellulose stabilized iron nanoparticles for in situ destruction of chlorinated solvents in source zones Water Res., 44 (2010), pp. 2360-2370 
Hoag et al., 2009

G.E. Hoag, J.B. Collins, J.L. Holcomb, J.R. Hoag, M.N. Nadagouda, R.S. Varma

Degradation of bromothymol blue by 'greener' nano-scale zero-valent iron synthesized using tea polyphenols

J. Mater. Chem., 19 (2009), pp. 8671-8677

Hoerle et al., 2004

S. Hoerle, F. Mazaudier, P. Dillmann, G. Santarini

Advances in understanding atmospheric corrosion of iron. II. Mechanistic modelling of wet-dry cycles

Corros. Sci., 46 (2004), pp. 1431-1465

Huang et al., 2014

L. Huang, X. Weng, Z. Chen, M. Megharaj, R. Naidu

Green synthesis of iron nanoparticles by various tea extracts: comparative study of the reactivity

Spectrochim. Acta A Mol. Biomol. Spectrosc., 130 (2014), pp. 295-301

Husen and Siddiqi, 2014

A. Husen, K.S. Siddiqi

Phytosynthesis of nanoparticles: concept, controversy and application

Nanoscale Res. Lett., 9 (2014), p. 229

Kasel et al., 2013

D. Kasel, S.A. Bradford, J. Simunek, M. Heggen, H. Vereecken, E. Klumpp

Transport and retention of multi-walled carbon nanotubes in saturated porous media: effects of input concentration and grain size Water Res., 47 (2013), pp. 933-944

Kharisov et al., 2012

B.I. Kharisov, H.V.R. Dias, O.V. Kharissova, V. Manuel Jimenez-Perez, B. Olvera Perez, B. Munoz Flores Iron-containing nanomaterials: synthesis, properties, and environmental applications

RSC Adv., 2 (2012), pp. 9325-9358

Kozma et al., 2016

G. Kozma, A. Ronavari, Z. Konya, A. Kukovecz

Environmentally benign synthesis methods of zero-valent iron nanoparticles

ACS Sustain. Chem. Eng., 4 (2016), pp. 291-297 
Li et al., 2017

S. Li, W. Wang, F. Liang, W.-X. Zhang

Heavy metal removal using nanoscale zero-valent iron (nZVI): theory and application

J. Hazard. Mater., 322 (2017), pp. 163-171

Liang et al., 2013

Y. Liang, S.A. Bradford, J. Simunek, H. Vereecken, E. Klumpp

Sensitivity of the transport and retention of stabilized silver nanoparticles to physicochemical factors

Water Res., 47 (2013), pp. 2572-2582

Liu and Lowry, 2006

Y. Liu, G.V. Lowry

Effect of particle age (Fe-o content) and solution pH on NZVI reactivity: $\mathrm{H}-2$ evolution and TCE dechlorination

Environ. Sci. Technol., 40 (2006), pp. 6085-6090

Liu et al., 2005

Y.Q. Liu, S.A. Majetich, R.D. Tilton, D.S. Sholl, G.V. Lowry

TCE dechlorination rates, pathways, and efficiency of nanoscale iron particles with different properties

Environ. Sci. Technol., 39 (2005), pp. 1338-1345

Machado et al., 2013

S. Machado, S.L. Pinto, J.P. Grosso, H.P.A. Nouws, J.T. Albergaria, C. Delerue-Matos

Green production of zero-valent iron nanoparticles using tree leaf extracts

Sci. Total Environ., 445 (2013), pp. 1-8

Machado et al., 2014

S. Machado, J.P. Grosso, H.P.A. Nouws, J.T. Albergaria, C. Delerue-Matos

Utilization of food industry wastes for the production of zero-valent iron nanoparticles

Sci. Total Environ., 496 (2014), pp. 233-240

Machado et al., 2015

S. Machado, J.G. Pacheco, H.P.A. Nouws, J.T. Albergaria, C. Delerue-Matos

Characterization of green zero-valent iron nanoparticles produced with tree leaf extracts

Sci. Total Environ., 533 (2015), pp. 76-81 
Matlochova et al., 2013

A. Matlochova, D. Placha, N. Rapantova

The application of nanoscale materials in groundwater

Remediation, 22 (2013)

Mystrioti et al., 2015

C. Mystrioti, D. Sparis, N. Papasiopi, A. Xenidis, D. Dermatas, M. Chrysochoou

Assessment of polyphenol coated nano zero valent iron for hexavalent chromium removal from contaminated waters

Bull. Environ. Contam. Toxicol., 94 (2015), pp. 302-307

Nowack and Bucheli, 2007

B. Nowack, T.D. Bucheli

Occurrence, behavior and effects of nanoparticles in the environment

Environ. Pollut., 150 (2007), pp. 5-22

Nurmi et al., 2005

J.T. Nurmi, P.G. Tratnyek, V. Sarathy, D.R. Baer, J.E. Amonette, K. Pecher, et al.

Characterization and properties of metallic iron nanoparticles: spectroscopy, electrochemistry, and kinetics

Environ. Sci. Technol., 39 (2005), pp. 1221-1230

Phenrat et al., 2007

T. Phenrat, N. Saleh, K. Sirk, R.D. Tilton, G.V. Lowry

Aggregation and sedimentation of aqueous nanoscale zerovalent iron dispersions

Environ. Sci. Technol., 41 (2007), pp. 284-290

Quinn et al., 2005

J. Quinn, C. Geiger, C. Clausen, K. Brooks, C. Coon, S. O'Hara, et al.

Field demonstration of DNAPL dehalogenation using emulsified zero-valent iron

Environ. Sci. Technol., 39 (2005), pp. 1309-1318

Ryan and Elimelech, 1996

J.N. Ryan, M. Elimelech

Colloid mobilization and transport in groundwater

Colloids Surf. A Physicochem. Eng. Asp., 107 (1996), pp. 1-56 
Saberinasr et al., 2016

A. Saberinasr, M. Rezaei, M. Nakhaei, S.M. Hosseini

Transport of CMC-stabilized nZVI in saturated sand column: the effect of particle concentration and soil grain size

Water Air Soil Pollut., 227 (2016)

Saiers and Lenhart, 2003

J.E. Saiers, J.J. Lenhart

Colloid mobilization and transport within unsaturated porous media under transient-flow conditions

Water Resour. Res., 39 (2003)

Sakulchaicharoen et al., 2010

N. Sakulchaicharoen, D.M. O'Carroll, J.E. Herrera

Enhanced stability and dechlorination activity of pre-synthesis stabilized nanoscale FePd particles

J. Contam. Hydrol., 118 (2010), pp. 117-127

Saleh et al., 2005

N. Saleh, T. Sarbu, K. Sirk, G.V. Lowry, K. Matyjaszewski, R.D. Tilton

Oil-in-water emulsions stabilized by highly charged polyelectrolyte-grafted silica nanoparticles

Langmuir, 21 (2005), pp. 9873-9878

Saleh et al., 2007

N. Saleh, K. Sirk, Y. Liu, T. Phenrat, B. Dufour, K. Matyjaszewski, et al.

Surface modifications enhance nanoiron transport and NAPL targeting in saturated porous media

Environ. Eng. Sci., 24 (2007), pp. 45-57

Sarathy et al., 2008

V. Sarathy, P.G. Tratnyek, J.T. Nurmi, D.R. Baer, J.E. Amonette, C.L. Chun, et al.

Aging of iron nanoparticles in aqueous solution: effects on structure and reactivity

J. Phys. Chem. C, 112 (2008), pp. 2286-2293

Schrick et al., 2004

B. Schrick, B.W. Hydutsky, J.L. Blough, T.E. Mallouk

Delivery vehicles for zerovalent metal nanoparticles in soil and groundwater

Chem. Mater., 16 (2004), pp. 2187-2193 
Song and Carraway, 2005

H. Song, E.R. Carraway

Reduction of chlorinated ethanes by nanosized zero-valent iron: kinetics, pathways, and effects of reaction conditions

Environ. Sci. Technol., 39 (2005), pp. 6237-6245

Steenhuis et al., 2006

T.S. Steenhuis, A. Dathe, Y. Zevi, J.L. Smith, B. Gao, S.B. Shaw, et al.

Biocolloid retention in partially saturated soils

Biologia, 61 (2006), pp. S229-S233

Sun et al., 2015

Y. Sun, B. Gao, S.A. Bradford, L. Wu, H. Chen, X. Shi, et al.

Transport, retention, and size perturbation of graphene oxide in saturated porous media: effects of input concentration and grain size

Water Res., 68 (2015), pp. 24-33

Tiede et al., 2009

K. Tiede, M. Hassellov, E. Breitbarth, Q. Chaudhry, A.B.A. Boxall

Considerations for environmental fate and ecotoxicity testing to support environmental risk assessments for engineered nanoparticles

J. Chromatogr. A, 1216 (2009), pp. 503-509

Tiraferri and Sethi, 2009

A. Tiraferri, R. Sethi

Enhanced transport of zerovalent iron nanoparticles in saturated porous media by guar gum

J. Nanopart. Res., 11 (2009), pp. 635-645

Tosco et al., 2014

T. Tosco, M.P. Papini, C.C. Viggi, R. Sethi

Nanoscale zerovalent iron particles for groundwater remediation: a review

J. Clean. Prod., 77 (2014), pp. 10-21

Tourinho et al., 2012

P.S. Tourinho, C.A.M. van Gestel, S. Lofts, C. Svendsen, A.M.V.M. Soares, S. Loureiro

Metal-based nanoparticles in soil: fate, behavior, and effects on soil invertebrates

Environ. Toxicol. Chem., 31 (2012), pp. 1679-1692 
Tratnyek and Johnson, 2006

P.G. Tratnyek, R.L. Johnson

Nanotechnologies for environmental cleanup

Nano Today, 1 (2006), pp. 44-48

Varanasi et al., 2007

P. Varanasi, A. Fullana, S. Sidhu

Remediation of PCB contaminated soils using iron nano-particles

Chemosphere, 66 (2007), pp. 1031-1038

Wei et al., 2010

Y.-T. Wei, S.-C. Wu, C.-M. Chou, C.-H. Che, S.-M. Tsai, H.-L. Lien

Influence of nanoscale zero-valent iron on geochemical properties of groundwater and vinyl chloride degradation: a field case study

Water Res., 44 (2010), pp. 131-140

Zhang, 2003

W.X. Zhang

Nanoscale iron particles for environmental remediation: an overview

J. Nanopart. Res., 5 (2003), pp. 323-332

Zhang et al., 2011

M. Zhang, F. He, D. Zhao, X. Hao

Degradation of soil-sorbed trichloroethylene by stabilized zero valent iron nanoparticles: effects of sorption, surfactants, and natural organic matter

Water Res., 45 (2011), pp. 2401-2414

Zhao et al., 2016

X. Zhao, W. Liu, Z. Cai, B. Han, T. Qian, D. Zhao

An overview of preparation and applications of stabilized zero-valent iron nanoparticles for soil and groundwater remediation

Water Res., 100 (2016), pp. 245-266 